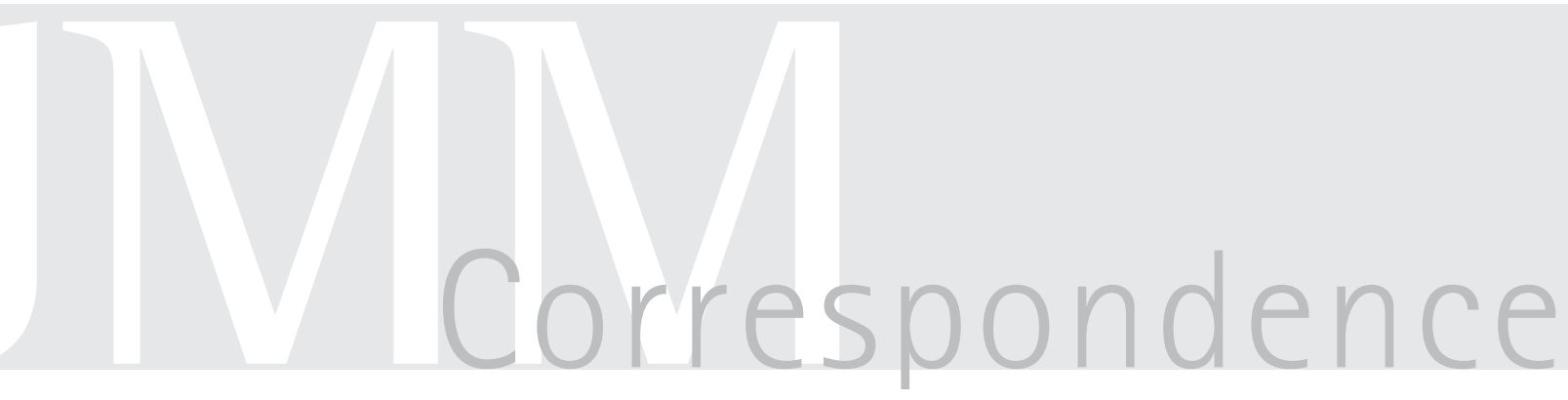

\title{
Helicobacter pylori infection in elderly Bulgarian patients
}

Helicobacter pylori infection causes chronic gastritis that can trigger peptic ulcer disease and gastric malignancy (Marshall, 1994).

The serious complications of peptic ulcers (bleeding or perforation) affect many elderly patients worldwide (Pilotto, 2001). Successful eradication of the infection results in ulcer healing (Adamek et al., 1998) and may prevent the progression of intestinal metaplasia in elderly patients (Pilotto \& Malfertheiner, 2002); however, clinical interest in $H$. pylori infection in elderly people remains low (Pilotto \& Salles, 2002). Furthermore, gastroduodenal diseases are associated with other diseases in many old patients. The aim of this study was to evaluate the prevalence of $H$. pylori infection and primary $H$. pylori resistance to antimicrobial agents in elderly Bulgarian patients with gastroduodenal diseases.

A total of 127 consecutive elderly patients (60-89 years) with gastroduodenal diseases between January 1996 and July 2003 were evaluated. All were admitted because of abdominal complaints, mostly consisting of epigastric pain and dyspepsia. No patient had been treated previously for $H$. pylori infection. The classification of diseases as chronic gastritis, erosive gastritis, duodenal ulcer, stomach ulcer and stomach cancer was based on endoscopic findings, histology and clinical signs (Table 1). Endoscopy was performed with an Olympus GIF P20 (biopsy forceps K19). Two stomach biopsy specimens per patient were taken at $3-5 \mathrm{~cm}$ from the pylorus. Specimens were transported in Stuart's transport medium (Merck) for less than $5 \mathrm{~h}$. Susceptibility to antimicrobial agents of $92 \mathrm{H}$. pylori isolates was investigated.

A smear was prepared from one part of the specimens by scraping the biopsy on a slide. The smear was used for a modified Gram stain with carbol fuchsin as the counterstain. For the urease test, another part of the biopsy specimen was placed in urea $(10 \%)$ agar medium as described previously (Boyanova et al., 1996), incubated at $37^{\circ} \mathrm{C}$ and observed for colour change after $30 \mathrm{~min}$ and $3 \mathrm{~h}$. The remaining part of the biopsy specimen was homogenized in $0.1 \mathrm{ml}$ sterile saline with sterile needles and inoculated onto blood agar [Columbia agar base (Oxoid) or Brucella agar base (Becton Dickinson)] containing $10 \%$ defibrinated sheep blood and $1 \%$ Isovitalex (Becton Dickinson), with or without $H$. pylori selective supplement,

Table 1. Patients involved in the present study

\begin{tabular}{|c|c|c|c|c|}
\hline \multirow[t]{2}{*}{ Patient group } & \multirow[t]{2}{*}{$n$} & \multicolumn{3}{|c|}{ H. pylori-positive ${ }^{*}$} \\
\hline & & $n$ & $\%$ & $95 \%$ CI of percentage \\
\hline All & 127 & 103 & $81 \cdot 1$ & $73 \cdot 5-88 \cdot 7$ \\
\hline \multicolumn{5}{|l|}{ By age } \\
\hline $60-69$ years & 80 & 64 & $80 \cdot 0$ & $71 \cdot 2-88 \cdot 8$ \\
\hline $70-79$ years & 43 & 35 & $81 \cdot 4$ & $69 \cdot 6-93 \cdot 2$ \\
\hline $80-89$ years & 4 & 4 & $100 \cdot 0$ & $72 \cdot 4-100 \cdot 0$ \\
\hline \multicolumn{5}{|l|}{ By condition } \\
\hline Chronic gastritis & 65 & 51 & $78 \cdot 5$ & $68 \cdot 5-88 \cdot 5$ \\
\hline Erosive gastritis & 24 & 19 & $79 \cdot 2$ & $62 \cdot 6-95 \cdot 8$ \\
\hline Duodenal ulcer & 22 & 22 & $100 \cdot 0$ & $92 \cdot 1-100 \cdot 0$ \\
\hline Stomach ulcer & 9 & 6 & $66 \cdot 7$ & $34 \cdot 1-99 \cdot 3$ \\
\hline Stomach cancer & 7 & 5 & $71 \cdot 4$ & $35 \cdot 2-100 \cdot 0$ \\
\hline
\end{tabular}

${ }^{\star}$ Specimens were considered positive for $H$. pylori only if culture or two of the other three diagnostic methods were positive.

containing $10 \mu \mathrm{g}$ vancomycin, $5 \mu \mathrm{g}$ trimethoprim, $5 \mu \mathrm{g}$ cefsulodin and $5 \mu \mathrm{g}$ amphotericin $\mathrm{B} \mathrm{ml}^{-1}[H$. pylori selective supplement (Dent); Oxoid]. One selective and one non-selective medium plate were used for primary culture of biopsy specimens. Plates were incubated for 12 days in a microaerobic atmosphere. $H$. pylori was identified by Gram staining of suspect colonies, lack of aerobic growth on blood-agar plates and testing for the presence of urease, oxidase and catalase. Specimens were considered as H. pylori positive only if culture or two of the other three diagnostic methods gave positive results.

In the screening agar method (SAM), two drops (approx. $60 \mu \mathrm{l}$ ) of $H$. pylori suspensions, prepared in Mueller-Hinton broth (NCIPD) to obtain McFarland turbidity standard 3-4, were inoculated on a quarter of the surface of Mueller-Hinton blood-agar plates (NCIPD) containing $1 \%$ Isovitalex and one of the following drug concentrations: 8,16 or $32 \mu \mathrm{g}$ metronidazole $\mathrm{ml}^{-1}, 0 \cdot 25,0 \cdot 5,1$ or $2 \mu \mathrm{g}$ clarithromycin or azithromycin $\mathrm{ml}^{-1}, 0 \cdot 5,1$ or $2 \mu \mathrm{g}$ amoxicillin $\mathrm{ml}^{-1}, 1 \mu \mathrm{g}$ ciprofloxacin $\mathrm{ml}^{-1}$ or $4 \mu \mathrm{g}$ tetracycline $\mathrm{ml}^{-1}$.

Antimicrobial agents were obtained from Sigma (amoxicillin, metronidazole and tetracycline), Abbott Laboratories (clarithromycin), Balkanpharma (azithromycin) and Bayer Pharma (ciprofloxacin). The plates were incubated microaerobically at $37^{\circ} \mathrm{C}$ for 3 days. If $H$. pylori growth appeared on the plate, the isolate was considered to be resistant to the corresponding drug. Non-selective medium plates were used as a control of strain viability. Primary resistance rates of 92 strains from elderly patients with gastroduodenal diseases were compared with those of 423 isolates from adults aged $19-59$ years.

Minimal inhibitory concentrations (MICs) of clarithromycin were determined for 48 strains from elderly patients and were compared with those of 70 isolates from adults aged $19-59$ years. McFarland 3 suspensions were prepared in MuellerHinton broth and $0.5 \mathrm{ml}$ volumes were used 
to flood Mueller-Hinton blood-agar plates containing $1 \%$ Isovitalex without antibiotics. E test strips (AB Biodisk) were placed on the plates and they were incubated for $48-72 \mathrm{~h}$ under microaerobic conditions. The results were read according to the supplier's recommendations. The breakpoints used to define resistance by SAM and $\mathrm{E}$ test were: $>8 \mu \mathrm{g}$ metronidazole $\mathrm{ml}^{-1},>1 \mu \mathrm{g}$ clarithromycin and azithromycin $\mathrm{ml}^{-1},>0.5 \mu \mathrm{g}$ amoxicillin $\mathrm{ml}^{-1},>4 \mu \mathrm{g}$ tetracycline $\mathrm{ml}^{-1}$ and $>1 \mu \mathrm{g}$ ciprofloxacin $\mathrm{ml}^{-1}$ (Megraud et al., 1999; NCCLS, 2000). Metronidazole resistance was determined from SAM results only.

Differences between patients with susceptible and resistant strains were assessed by $\chi^{2}$ test with Yates's correction.

Scant data are available concerning both the incidence of $H$. pylori infection and the susceptibility patterns of isolates from elderly patients with dyspeptic complaints (Parsons et al., 2001; Pilotto, 2001; Pilotto \& Malfertheiner, 2002; Pilotto \& Salles, 2002). In the present study, $H$. pylori infection was found in $103(81 \cdot 1 \%)$ elderly patients with gastroduodenal diseases (Table 1). Culture failed to detect $H$. pylori in nine $(8.7 \%)$ of the specimens that were positive with other diagnostic tests, probably as a result of the increase in gastric atrophy (Pilotto \& Salles, 2002) and intestinal metaplasia or previous treatment for other infections in the older age group. Nevertheless, $H$. pylori infection was found in $>78 \%$ of Bulgarian elderly patients with chronic gastritis and in $90.3 \%$ of those with peptic ulcers, unlike several other studies that have reported H. pylori prevalence in elderly patients with peptic ulcers as 50-78 \% (Pilotto, 2001; Pilotto \& Malfertheiner, 2002; Pilotto \& Salles, 2002). There was no statistically significant difference between the prevalence of $H$. pylori infection in elderly patients aged 60-69 years and that in older patients $(P>0 \cdot 20)$.

According to recent studies, better $H$. pylori eradication has been obtained in patients aged over 60 years (except for type 2 diabetic patients) than in younger patients (Broutet et al., 2003; Sargyn et al., 2003). In the present study, the resistance rates to metronidazole, tetracycline and newer macrolides in elderly patients were similar to those in younger adults $(P>0 \cdot 20)$. Amoxicillin resistance was not detected in the elderly but was found in $1 \%$ of strains isolated from younger adults (Table 2). Although ciprofloxacin is not currently used in treatment regimens for $H$. pylori eradication, a slightly higher prevalence of ciprofloxacin resistance was detected in older $(8.9 \%)$ than in younger adults $(6 \cdot 1 \%)$ $(P>0 \cdot 20)$. Elderly patients are at higher risk of hospitalization and treatment for respiratory or urinary infections (Pilotto \& Salles, 2002). This could explain the rate of ciprofloxacin resistance in older patients.

Table 2. Primary and combined resistance in $H$. pylori isolates from elderly and other adult patients with gastroduodenal disease

Other adults refers to patients aged 19-59 years. Confidence intervals (CI) refer to percentage values.

\begin{tabular}{|llccc|}
\hline Agent & Patient group & Strains tested $(\boldsymbol{n})$ & Resistance $(\%)$ & $\mathbf{9 5} \% \mathbf{C I}$ \\
\hline Metronidazole & Elderly & 92 & $28 \cdot 3$ & $19 \cdot 0-37 \cdot 6$ \\
& Other adults & 423 & $28 \cdot 8$ & $24 \cdot 5-33 \cdot 1$ \\
Clarithromycin & Elderly & 90 & $12 \cdot 2$ & $5 \cdot 4-19 \cdot 0$ \\
& Other adults & 415 & $11 \cdot 3$ & $8 \cdot 3-14 \cdot 3$ \\
Azithromycin & Elderly & 59 & $15 \cdot 2$ & $6 \cdot 0-24 \cdot 4$ \\
& Other adults & 253 & $16 \cdot 2$ & $11 \cdot 7-20 \cdot 7$ \\
Amoxicillin & Elderly & 88 & 0 & $0-2 \cdot 1$ \\
& Other adults & 361 & $1 \cdot 1$ & $0-2 \cdot 2$ \\
Ciprofloxacin & Elderly & 45 & $8 \cdot 9$ & $0 \cdot 5-17 \cdot 3$ \\
& Other adults & 212 & $6 \cdot 1$ & $2 \cdot 9-9 \cdot 3$ \\
Tetracycline & Elderly & 88 & $4 \cdot 5$ & $0 \cdot 2-8 \cdot 8$ \\
& Other adults & 419 & $4 \cdot 3$ & $2 \cdot 4-6 \cdot 2$ \\
Metronidazole + & Elderly & 86 & $4 \cdot 6$ & $0 \cdot 2-9 \cdot 1$ \\
clarithromycin & Other adults & 411 & $4 \cdot 3$ & $2 \cdot 3-6 \cdot 3$ \\
\hline
\end{tabular}

According to several authors, the overall rate of metronidazole resistance has shown a tendency to decrease with age, whereas the prevalence of clarithromycin resistance has not been associated with age (Fraser et al., 1999; Parsons et al., 2001). In the present study, the MIC values of clarithromycin for strains from elderly patients were similar to those from younger adults. Although the prevalence of combined resistance to metronidazole and clarithromycin in the elderly $(4.6 \%)$ was similar to that in other adults $(4.3 \%)$, fewer $(52.6 \%)$

metronidazole-resistant strains from elderly patients had high levels of metronidazole resistance (MIC $>32 \mu \mathrm{g} \mathrm{ml}^{-1}$ ) than those from younger adults $(78 \cdot 7 \%)(P<0 \cdot 001)$.

In conclusion, because $H$. pylori infection was detected in most elderly patients with gastroduodenal diseases and the primary resistance rates in the elderly patients were similar to those in younger adults, microbiological diagnostic tests for $H$. pylori infection in this poorly studied group of elderly patients with dyspeptic complaints are necessary and beneficial.

\section{Lyudmila Boyanova, ${ }^{1}$ Nikolai Katsarov, ${ }^{2}$ Galia Gergova, ${ }^{1}$ Rossen Nikolov, ${ }^{3}$ Sirigan Derejian, ${ }^{3}$ Zoya Spassova, ${ }^{3}$ Ivan Mitov ${ }^{1}$ and Zacharii Krastev $^{3}$ \\ ${ }^{1}$ Department of Microbiology, Medical University of Sofia, Sofia, Bulgaria \\ ${ }^{2}$ Second Surgery Department of Alexander Hospital, Sofia, Bulgaria \\ ${ }^{3}$ Department of Gastroenterology, University Hospital 'St Ivan Rilski', Sofia, Bulgaria}

Correspondence: Lyudmila Boyanova (Iboyanova@hotmail.com)

Adamek, R. J., Suerbaum, S., Pfaffenbach, B. \& Opferkuch, W. (1998). Primary and acquired Helicobacter pylori resistance to clarithromycin, metronidazole, and amoxicillin - influence on treatment outcome. Am J Gastroenterol 93, 386-389.

Boyanova, L., Stancheva, I., Todorov, D. \& 7 other authors (1996). Comparison of three urease tests for detection of Helicobacter pylori in gastric biopsy specimens. Eur J Gastroenterol Hepatol 8, 911-914.

Broutet, N., Tchamgoue, S., Pereira, E., Lamouliatte, H., Salamon, R. \& Megraud, F. (2003). Risk factors for failure of Helicobacter pylori therapy -results of an individual data analysis of 2751 patients. Aliment Pharmacol Ther 17, 99-109. 
Fraser, A. G., Moore, L., Hackett, M. \& Hollis, B. (1999). Helicobacter pylori treatment and antibiotic susceptibility: results of a five-year audit. Aust N Z J Med 29, 512-516.

Marshall, B. J. (1994). Helicobacter pylori. Am J Gastroenterol 89 (Suppl.), S116-S128.

Megraud, F., Lehn, N., Lind, T. \& 7 other authors (1999). Antimicrobial susceptibility testing of Helicobacter pylori in a large multicenter trial: the MACH 2 study. Antimicrob Agents Chemother 43, 2747-2752. NCCLS (2000). Performance standards for antimicrobial susceptibility testing. Tenth informational supplement. Approved standard M100-S10 (M7). Wayne, PA: National Committee for Clinical Laboratory Standards.

Parsons, H. K., Carter, M. J., Sanders, D. S., Winstanley, T. \& Lobo, A. J. (2001). Helico-

bacter pylori antimicrobial resistance in the United Kingdom: the effect of age, sex and socio-economic status. Aliment Pharmacol Ther 15, 1473-1478.

Pilotto, A. (2001). Helicobacter pyloriassociated peptic ulcer disease in older patients: current management strategies. Drugs Aging 18, 487-494.
Pilotto, A. \& Malfertheiner, P. (2002). Review article: an approach to Helicobacter pylori infection in the elderly. Aliment Pharmacol Ther 16, 683-691.

Pilotto, A. \& Salles, N. (2002). Helicobacter pylori infection in geriatrics. Helicobacter 7 (Suppl. 1), 56-62.

Sargyn, M., Uygur-Bayramicli, O., Sargyn, H., Orbay, E., Yavuzer, D. \& Yayla, A. (2003). Type 2 diabetes mellitus affects eradication rate of Helicobacter pylori. World J Gastroenterol 9 , $1126-1128$ 